\title{
Nanoscale
}

(A) Check for updates

Cite this: Nanoscale, 2019, 11, 7239

Received 18th December 2018

Accepted 8th March 2019

DOI: 10.1039/c8nr10191d

rsc.li/nanoscale

\section{High-performance electrolytic oxygen evolution with a seamless armor core-shell FeCoNi oxynitride $\uparrow$}

\author{
Jun Di, (D) a Huiyuan Zhu, ${ }^{b}$ Jiexiang Xia, (D) *a,c Jian Bao, (D) a Pengfei Zhang, ${ }^{c}$ \\ Shi-Ze Yang, (iD *d Huaming $\mathrm{Li}^{\mathrm{a}}$ and Sheng Dai iD *c
}

\begin{abstract}
Highly active, low-cost, and durable electrocatalysts for the water oxidation reaction are pivotal in energy conversion and storage schemes. Here we report a nitride-core, oxide-shell-armor structured FeCoNi oxynitride as an efficient oxygen evolution electrocatalyst with a homogeneous nitride $\left(\mathrm{Fe}_{0.70} \mathrm{CO}_{0.56} \mathrm{Ni}_{0.92} \mathrm{~N}_{1.0} \mathrm{O}_{0.06}\right)$ core and an oxide $\left(\mathrm{Fe}_{0.48} \mathrm{Co}_{0.1} \mathrm{Ni}_{0.21} \mathrm{~N}_{0.05} \mathrm{O}_{1.0}\right)$ shell. The catalyst demonstrated excellent activity for the oxygen evolution reaction with a current density of $10 \mathrm{~mA} \mathrm{~cm} \mathrm{~cm}^{-2}$ at a low overpotential of $0.291 \mathrm{~V}$ in alkaline media $(1 \mathrm{M} \mathrm{KOH})$, which is superior to the activities of commercial $\mathrm{IrO}_{2}, \mathrm{RuO}_{2}$, and $\mathrm{Pt} / \mathrm{C}$ catalysts and comparable to those of state-of-the-art catalysts (e.g., NiFe-LDH, $\mathrm{NiCO}_{2} \mathrm{O}_{4}, \mathrm{O}-\mathrm{NiCoFe}-\mathrm{LDH}$ ). Density functional theory simulations suggested that the incorporation of multiple metal elements can indeed improve the reaction energetics with a synergistic effect from the core-shell structure. This unique structure of a nitride-core with a oxide-shell presents a new form of multimetallic oxynitride with compelling performance in electrolytic oxygen evolution.
\end{abstract}

Ever-growing energy demand and growing carbon emissions have made it urgent to find alternatives to the traditional fossil fuels currently consumed in huge amounts. ${ }^{1-4}$ Electrocatalytic water splitting is an appealing route to produce a renewable hydrogen energy source, which could simultaneously mitigate energy and environmental pollution problems. ${ }^{5}$ Unfortunately, the efficiency of electrolytic water splitting is greatly limited due to the sluggish kinetics of the multi-electron step involved in the oxygen evolution reaction (OER). ${ }^{6-8}$ Even for the most efficient precious-metal catalysts such as ruthenium $(\mathrm{Ru})$ and iridium (Ir) oxides, ${ }^{9}$ a substantial overpotential is still required to acquire the desired current densities. ${ }^{10}$ Therefore, designing and developing efficient electrocatalysts that are low in cost for the OER present a grand challenge for the electrocatalytic water splitting process.

Transition-metal-based materials such as oxides, ${ }^{11}$ hydroxides, ${ }^{12}$ phosphates, ${ }^{13}$ chalcogenides, ${ }^{14}$ and perovskites ${ }^{15}$ have

\footnotetext{
${ }^{a}$ School of Chemistry and Chemical Engineering, Institute for Energy Research, Jiangsu University, 301 Xuefu Road, Zhenjiang, 212013, P. R. China.

E-mail: xjx@ujs.edu.cn

${ }^{b}$ Department of Chemical Engineering, Virginia Tech, Blacksburg, VA, USA

${ }^{c}$ Chemical Sciences Division, Oak Ridge National Laboratory, Oak Ridge, USA. E-mail: dais@ornl.gov

${ }^{d}$ Materials Science and Technology Division, Oak Ridge National Laboratory, USA.

E-mail: ananyjlo@gmail.com

$\dagger$ Electronic supplementary information (ESI) available. See DOI: 10.1039/ c8nr10191d
}

been widely studied as potential alternative OER electrocatalysts owing to their Earth-abundance, low cost, and environmental benignity. In particular, recent studies have found that metal nitrides, especially $\mathrm{Ni}_{3} \mathrm{~N}$ and $\mathrm{Co}_{4} \mathrm{~N}$, can serve as efficient OER catalysts because of the outstanding electroconductivity enabled by their metal-like features, potentially outperforming the well-studied metal oxide, hydroxide/phosphate systems. ${ }^{16,17}$ Nevertheless, these metal nitrides are thermodynamically less stable than metal oxides under oxidizing potentials, leading to the easy formation of passivation layers of oxides/hydroxides in oxidative aqueous environments. ${ }^{17}$ This surface oxidation process has been confirmed on metal nitride catalysts during the OER process. ${ }^{18}$ Therefore, the current transition-metal nitride systems still cannot meet the requirements for the OER necessary for them to be viably applied. Some recent studies have employed a binary system, including $\mathrm{NiCo} \mathrm{LDH}^{19}$ and $\mathrm{NiCo}_{2} \mathrm{O}_{4},{ }^{20}$ to promote OER catalysis. In this effort, we envision that Ni-Co bimetal nitrides with a homogeneous element dispersion and a protective shell might show a synergistic effect, further promoting the OER performance.

More importantly, previous reports have shown that iron (Fe) can have an important modulating effect on nickel (Ni) or cobalt (Co)-based materials to increase the OER activity. ${ }^{21,22}$ The adsorption energy of $\mathrm{OH}$, an important OER intermediate, is too weak on either Co-based or Ni-based material surfaces, and introducing Fe can promote the adsorption of $\mathrm{OH}^{10,23} \mathrm{In}$ 
addition, $\mathrm{Fe}$ is more vulnerable to oxidation than is $\mathrm{Co}$ or $\mathrm{Ni}$ and may serve as a sacrificed species in the multimetallic structure with $\mathrm{Ni}$ and Co. Our strategy was to incorporate an Fe oxide armor layer on a nitride surface to boost the catalyst's stability for the OER. Once $\mathrm{Fe}$ is introduced into $\mathrm{Ni}-\mathrm{Co}$ bimetal nitrides, the synergistic interplay among $\mathrm{Fe}$, Co, and $\mathrm{Ni}$ creates a preferable local coordination environment and an electronic structure that optimizes the adsorption energy of the oxygenated species; at the same time, the Fe oxide armor shell protects and maintains the integrity of the active $\mathrm{Ni}-\mathrm{Co}$ nitride matrix.

Experimentally, FeCoNi oxynitride was synthesized by solvothermal and the gradient temperature control under a particular atmosphere methods. Briefly, the multimetallic hydroxide precursor was firstly prepared and converted to an oxynitride by nitridation. Based on the fact that the formation temperature of iron nitrides is higher than that of $\mathrm{Ni}$ and Co nitrides, here we employed a moderate temperature of $400{ }^{\circ} \mathrm{C}$ for the nitridation of the precursor to form Fe-doped Ni/Co nitrides and oxides in situ on their surfaces. As a result, an armor-type nitride-core, oxide-shell (core-shell) structure was successfully constructed and it showed a largely enhanced OER activity compared with its single-metal or bimetal counterparts. The armor-type FeCoNi oxynitride materials afforded a current density of $10 \mathrm{~mA} \mathrm{~cm}{ }^{-2}$ at a low overpotential of only $0.291 \mathrm{~V}$, superior to those of commercial $\mathrm{IrO}_{2}, \mathrm{RuO}_{2}$, and $\mathrm{Pt} / \mathrm{C}$ catalysts under identical experimental conditions, and comparable to or even better than the values for state-of-the-art catalysts.
The crystalline structures of the as-prepared FeCoNi oxynitride and its single-component counterparts were determined by X-ray diffraction (XRD) analysis. Pure $\mathrm{Ni}_{3} \mathrm{~N}$ and $\mathrm{Co}_{2} \mathrm{~N}$ were prepared via nitridation of the corresponding hydroxide precursors (Fig. 1 and $\mathrm{S} 1 \dagger$ ); the peak of the Ni/Co bimetal nitride was more similar to that of $\mathrm{Ni}_{3} \mathrm{~N}$ (Fig. S1c $\dagger$ ), which can be ascribed to the fact that Co entered into the crystal lattice of $\mathrm{Ni}_{3} \mathrm{~N}$ via doping. When Fe was introduced, an $\mathrm{Ni}_{3} \mathrm{~N}$-like peak was also observed with additional $\mathrm{Fe}_{3} \mathrm{O}_{4}$ peaks (Fig. 1a).

To characterize the electronic interactions within the FeCoNi oxynitride, X-ray photoelectron spectroscopy (XPS) measurements were performed for the FeCoNi oxynitride material; the results are shown in Fig. $1 \mathrm{~b}-\mathrm{d}$ and S2. $\dagger$ The XPS results demonstrate the presence of the elements $\mathrm{Fe}, \mathrm{Co}, \mathrm{Ni}, \mathrm{N}$, and $\mathrm{O}$ in the FeCoNi oxynitride materials. Compared with $\mathrm{Co}_{2} \mathrm{~N}$, the Co $2 \mathrm{p} 3 / 2$ and Co $2 \mathrm{p} 1 / 2$ peaks in the XPS spectrum of the FeCoNi oxynitride were positively shifted by about $1.0 \mathrm{eV}$ (Fig. 1b). Compared with $\mathrm{Ni}_{3} \mathrm{~N}$, the $\mathrm{Ni} 2 \mathrm{p}$ peak of the FeCoNi oxynitride was positively shifted by about $0.51 \mathrm{eV}$ (Fig. 1c). The $\mathrm{N}$ 1s peak in the FeCoNi oxynitride displayed a positive shift (Fig. 1d). These results suggest the existence of strong electronic interactions involving $\mathrm{Fe}$, Co, and Ni tri-components in the FeCoNi oxynitride structure. The strong electronic interaction can be ascribed to the formation of a solid solution of an interior ternary metal. ${ }^{24}$ Simultaneously, compared with a binary CoNi nitride, the Co $2 \mathrm{p}$ and Ni 2 p peaks in the FeCoNi oxynitride also display a shift (Fig. S3†), further revealing the strong electron interactions among the Fe, Co, and Ni tri-com-
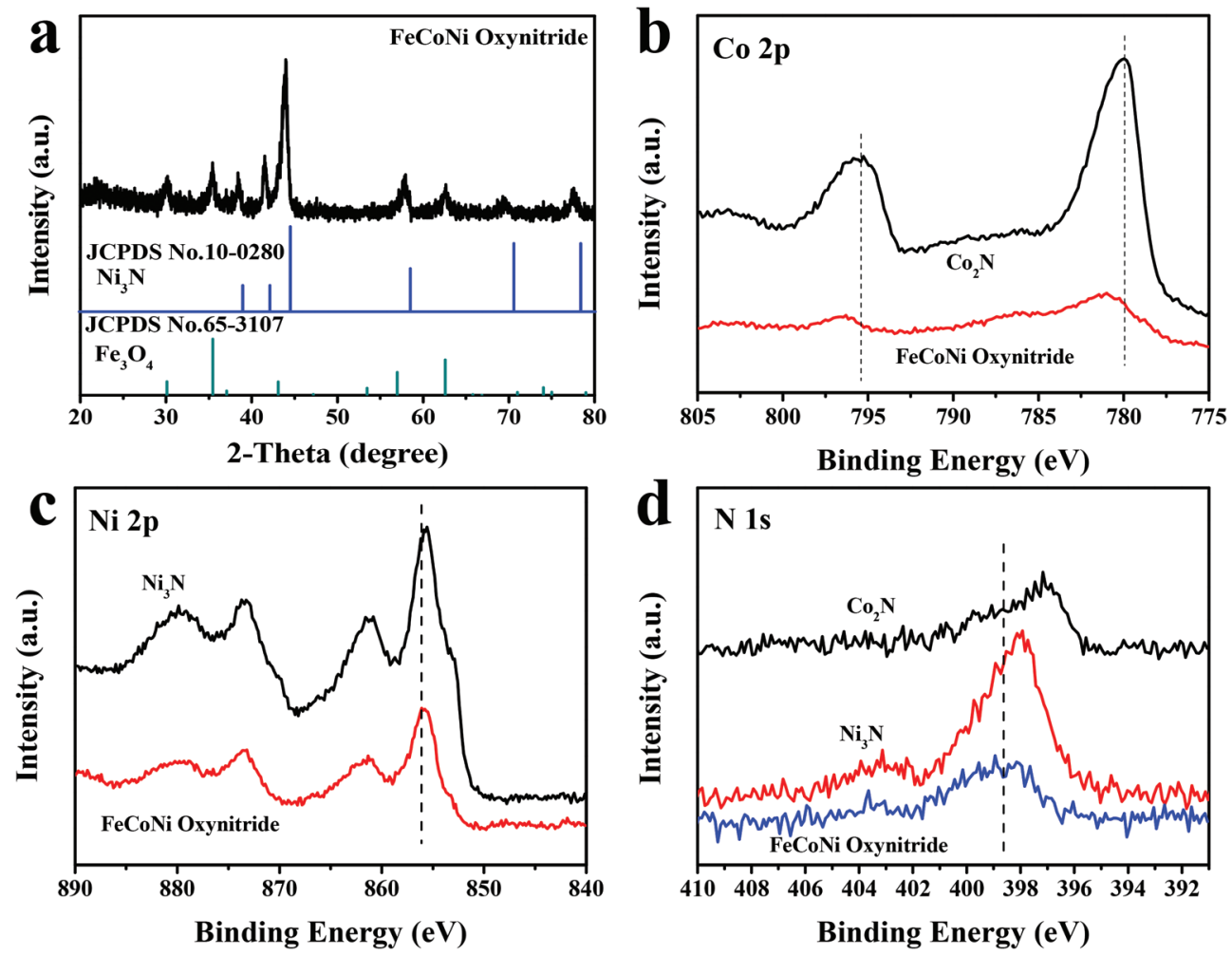

Fig. 1 (a) XRD patterns for the FeCoNi oxynitride; XPS spectra of (b) $\mathrm{Co} 2 \mathrm{p}$, (c) $\mathrm{Ni} 2 \mathrm{p}$, and (d) $\mathrm{N}$ 1s for the FeCoNi oxynitride, $\mathrm{Co}_{2} \mathrm{~N}$, and $\mathrm{Ni}_{3} \mathrm{~N}$. 
ponents in the FeCoNi oxynitride. The XPS valence band spectra show that the introduction of Fe could change the surface valence band structure of the nitride, which could be important for oxygen adsorption during the electrocatalytic process (Fig. S4†).

The formation and morphology of the prepared FeCoNi oxynitride (Fig. 2a) and single-component counterparts (Fig. S5 and S6†) were characterized by transmission electron microscopy (TEM) analysis. The single and binary nitrides show an irregular grain structure. Fig. 2b and c clearly depict the FeCoNi oxynitride nanoparticle morphology with an average diameter of about $30 \mathrm{~nm}$. In high-resolution bright field (BF) images (Fig. 2e), a dark core can be clearly seen at the center of the nanoparticle and uniform lighter shell caps
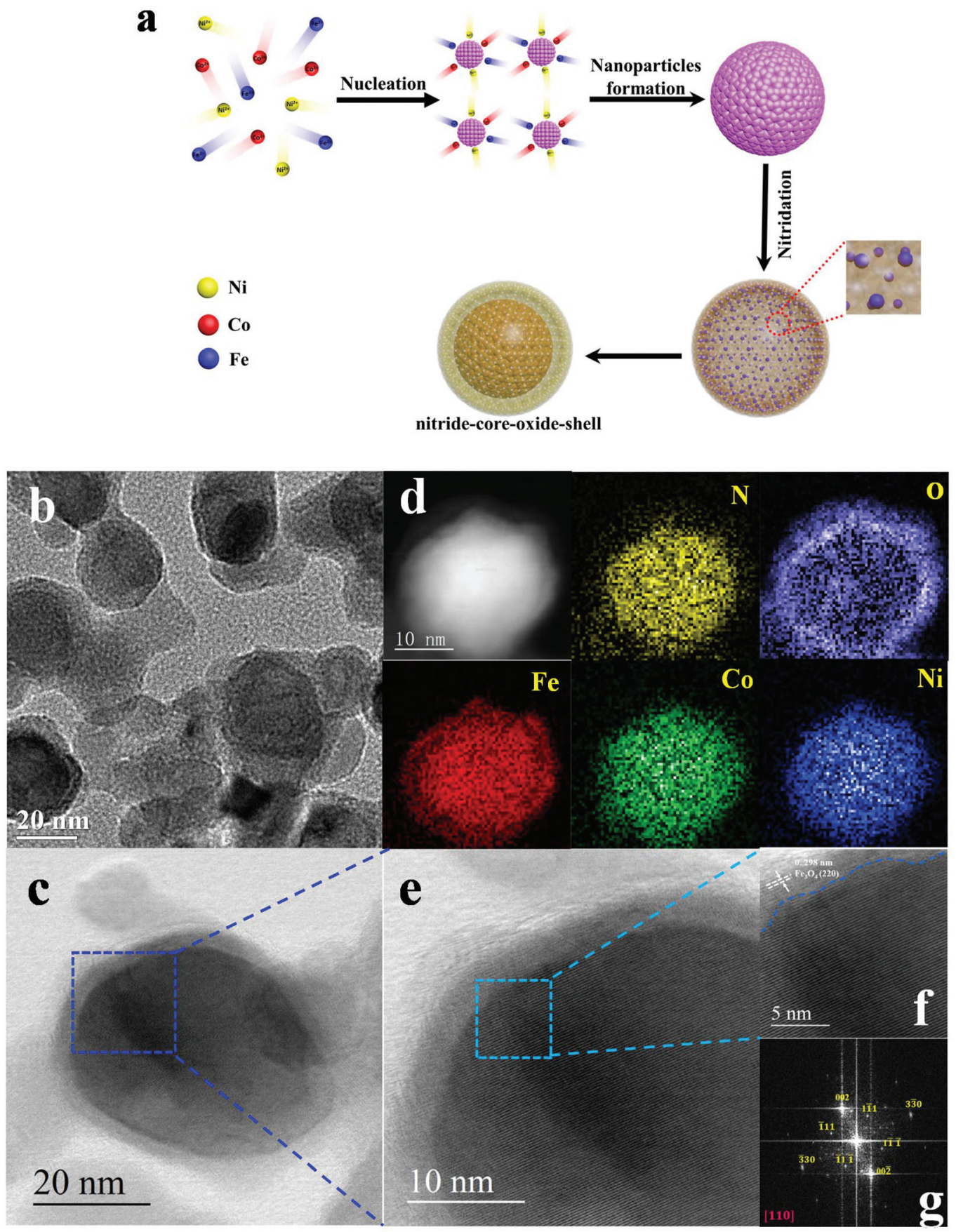

Fig. 2 (a) Illustration of the formation of nitride-core, oxide-shell FeCoNi oxynitride nanoparticles. STEM study of core-shell particles. (b) TEM image of nitride-core, oxide-shell FeCoNi oxynitride nanoparticles. (c) Higher-magnification STEM-BF images. (d) The corresponding EELS elemental mapping. (e) BF image of the blue upper region of the particle. (f) BF image showing the core-shell interface. (g) Fast Fourier transform of image $\mathrm{C}$ showing diffraction patterns along the [110] zone axis of nickel-cobalt-iron alloy nitrides $\left(\mathrm{Me}_{3} \mathrm{~N}\right)$. 
around it, suggesting the formation of a core-shell structure. ${ }^{25}$ To further reveal the core-shell structure, high-resolution imaging was carried out. The clear boundaries in the coreshell structure can be observed in Fig. 2f. The thickness of the oxide shell is about $3 \mathrm{~nm}$ with a lattice spacing of around $0.298 \mathrm{~nm}$, which agrees well with the crystallographic (220) spacing of $\mathrm{Fe}_{3} \mathrm{O}_{4}$, confirming the formation of an Fe oxide armor shell. The nitride-core structures are shown in Fig. 2g. A fast Fourier transform image (inset Fig. 2g) shows the diffraction patterns corresponding to the [110] zone axis of the $\mathrm{Me}_{3} \mathrm{~N}$ structure with the space group of $p 6322$, which agrees with the XRD results. Co and Fe are more likely to be doped into $\mathrm{Ni}_{3} \mathrm{~N}$ to form a solid solution-like nitride $\mathrm{Me}_{3} \mathrm{~N}$ structure in this core. Element mapping of the FeCoNi oxynitride by electron energy loss spectroscopy (EELS) (Fig. 2d and Fig. S7†) also shows a clear oxide shell and a nitride core. To further determine the components of the nitride-core, oxide-shell structure, aberration-corrected scanning transmission electron microscopy (STEM) with annular dark field (ADF) imaging and EELS measurements was carried out. A typical region with several core-shell nanoparticles is shown in the ADF images in Fig. S8. $\dagger$ Although the shapes of particles vary considerably in the ADF images, they share the common characteristics of the oxide shell and nitride core. The average chemical formulas of the nitride cores and oxide shells were determined to be $\mathrm{Fe}_{0.70} \mathrm{Co}_{0.56} \mathrm{Ni}_{0.92} \mathrm{~N}_{1.0} \mathrm{O}_{0.06}$ and $\mathrm{Fe}_{0.48} \mathrm{Co}_{0.1} \mathrm{Ni}_{0.21} \mathrm{~N}_{0.05} \mathrm{O}_{1.0}$, respectively (Tables $\mathrm{S} 1$ and $\mathrm{S} 2 \dagger$ ). The valence states of transition metals in the core and shell were analyzed using the $\mathrm{L}_{3}$ to $\mathrm{L}_{2}$ ratios in the EELS spectrum (Fig. S9†). The result shows that Fe, Co and Ni have a higher valence state in the shell than in the core (Table S3†).

To investigate the OER catalytic performance of the obtained FeCoNi oxynitride catalysts, the samples were deposited onto glass carbon electrodes $\left(0.284 \mathrm{mg} \mathrm{cm}^{-2}\right)$ and experiments were performed under a standard three-electrode system in $1.0 \mathrm{M} \mathrm{KOH}$. In the polarization curves (Fig. 3a), pristine $\mathrm{Co}_{2} \mathrm{~N}$, and $\mathrm{Ni}_{3} \mathrm{~N}$ show an insignificant OER response. After the formation of the Ni-Co bimetal nitride and introduction of Fe to $\mathrm{Co}_{2} \mathrm{~N}$ or $\mathrm{Ni}_{3} \mathrm{~N}$, the binary components displayed reduced onset potentials and higher current densities than their singlecomponent counterparts. These results suggest that building a Ni-Co bimetal nitride or Fe modification can improve the catalytic activity. Futhermore, the tri-metal FeCoNi oxynitride showed even better performance. Intriguingly, the FeCoNi oxynitride displayed an initial $\mathrm{O}_{2}$ evolution at a very small overpotential of $0.23 \mathrm{~V}$, much smaller than that of binary $\mathrm{FeNi}$ (0.29 V), binary CoNi (0.32), and binary FeCo (0.34 V). For comparison, commercial $\mathrm{IrO}_{2}, \mathrm{RuO}_{2}$, and $\mathrm{Pt} / \mathrm{C}(20 \mathrm{wt} \%$ platinum on Vulcan carbon black) were also investigated under the same conditions (Fig. 3b). Noticeably, the onset potential of the FeCoNi oxynitride was also much lower than those of $\operatorname{IrO}_{2}$, $\mathrm{RuO}_{2}$, and $\mathrm{Pt} / \mathrm{C}$, and the OER current density of the FeCoNi
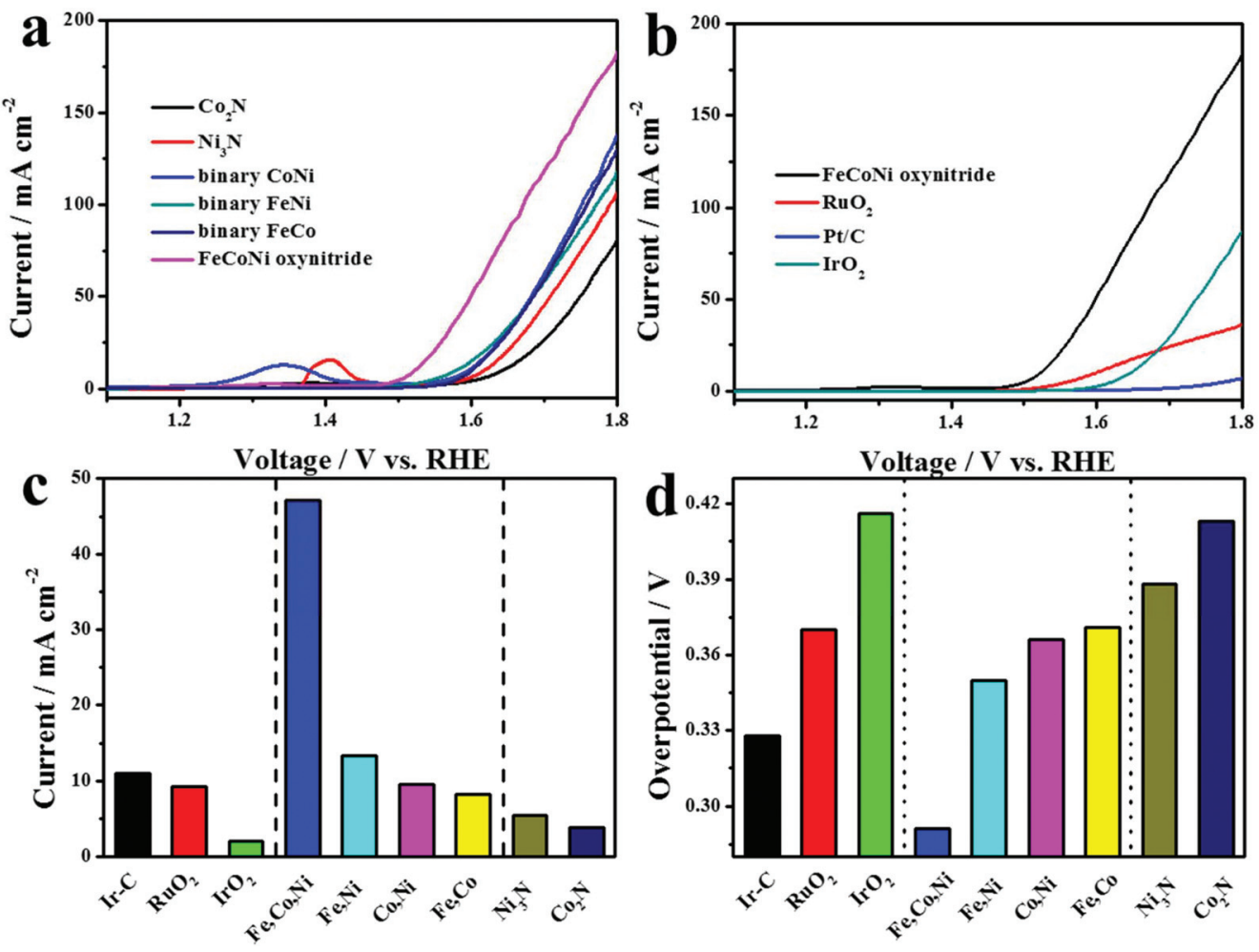

Fig. 3 (a) Polarization curves of the FeCoNi oxynitride, binary $\mathrm{FeCo}$, binary $\mathrm{FeNi}$, and binary $\mathrm{CoNi}, \mathrm{Co}_{2} \mathrm{~N}$, and $\mathrm{Ni}_{3} \mathrm{~N}$ samples for the OER at a scan rate of $5 \mathrm{mV} \mathrm{s}^{-1}\left(1 \mathrm{M} \mathrm{KOH}\right.$, without $i R$ correction). (b) Polarization curves of commercial IrO $\mathrm{I}_{2}, \mathrm{RuO}_{2}$, and Pt/C. (c) Comparison of the current achieved at a potential of $1.6 \mathrm{~V}$ vs. RHE (reversible hydrogen electrode). (d) The overpotential required for a current density of $10 \mathrm{~mA} \mathrm{~cm}^{-2}$ (without iR correction) and an Ir/C (20 wt\%) catalyst as a reference. ${ }^{12,28}$ 
oxynitride even exceeded those of commercial catalysts. By comparing the current density at a potential of $0.57 \mathrm{~V} v s . \mathrm{Ag} /$ $\mathrm{AgCl}$, it was found that under the same conditions, the FeCoNi oxynitride displayed a current density of $47.16 \mathrm{~mA} \mathrm{~cm}^{-2}$, much higher than those of $\mathrm{Co}_{2} \mathrm{~N}, \mathrm{Ni}_{3} \mathrm{~N}$, binary FeCo, binary CoNi, or binary FeNi (Fig. 3c). The current density acquired from the FeCoNi oxynitride was roughly 4.29, 5.07, and 23.35 times higher than the densities of commercial Ir-C, $\mathrm{RuO}_{2}$, and $\mathrm{IrO}_{2}$, respectively, at $1.56 \mathrm{~V} v s$. RHE.

The current density value of $10 \mathrm{~mA} \mathrm{~cm}{ }^{-2}$ is particularly important because it is the current density of a device with $10 \%$ solar-to-hydrogen conversion under 1-sun illumination. ${ }^{26}$ The overpotential $(\eta)$ required to achieve a $10 \mathrm{~mA} \mathrm{~cm}^{-2}$ current density was determined, and the result is shown in Fig. 3d. The FeCoNi oxynitride showed a required overpotential of $0.291 \mathrm{~V}$, exhibiting a lower required overpotential than $\mathrm{Co}_{2} \mathrm{~N}$ $(0.413 \mathrm{~V}), \mathrm{Ni}_{3} \mathrm{~N}(0.388 \mathrm{~V})$, binary FeCo $(0.371 \mathrm{~V})$, binary CoNi $(0.366 \mathrm{~V})$, and binary FeNi $(0.350 \mathrm{~V})$. Since the samples have similar BET specific surface areas, the obtained normalized intrinsic activity of catalysts still matches the original performance; thus the improved OER performance of the FeCoNi oxynitride may not be derived from the difference in specific surface areas (Fig. S10 and $\mathrm{S} 11 \dagger$ ). At the same time, the required overpotential of $0.291 \mathrm{~V}$ was also much lower than those of commercial Ir-C, $\mathrm{RuO}_{2}$, and $\mathrm{IrO}_{2}$. This overpotential places the FeCoNi oxynitride catalyst among the top tier of water oxidation catalysts in alkaline media, outperforming NiFe-LDH single-layer nanosheets $(0.302 \mathrm{~V}),{ }^{19}$ monolayer $\mathrm{Ni}_{0.75} \mathrm{~V}_{0.25}-\mathrm{LDH}(0.318 \mathrm{~V}),{ }^{27} \mathrm{NiCo}_{2} \mathrm{O}_{4}$ ultrathin nanosheets $(0.320 \mathrm{~V}),{ }^{28} \mathrm{CoMnP}$ nanoparticles $(0.330 \mathrm{~V}),{ }^{29} \mathrm{Co}_{3} \mathrm{O}_{4} / \mathrm{NiCo}_{2} \mathrm{O}_{4}$ double-shelled nanocages $(0.340 \mathrm{~V}),{ }^{30} \mathrm{Ni}-\mathrm{Co}$ mixed oxide cages $(0.380 \mathrm{~V}),{ }^{31} \mathrm{O}-\mathrm{NiCoFe}-\mathrm{LDH}(0.420 \mathrm{~V}){ }^{32}$ single-crystal $\mathrm{Co}_{3} \mathrm{O}_{4} @ \mathrm{CoO}(0.430 \mathrm{~V}),{ }^{33}$ and others (Table $\left.\mathrm{S} 4 \dagger\right)$. These results provide further evidence of the advantages of the novel FeCoNi oxynitride core-shell materials.

By compensating the raw data with the $i R$ losses, the OER behavior of the FeCoNi oxynitride was found to be even more impressive (Fig. 4a). At the same time, the OER performance of the FeCoNi oxynitride was further measured in a loweralkalinity solution ( $0.1 \mathrm{M} \mathrm{KOH})$ because some devices, such as metal-air batteries, often perform better in less basic solutions. Generally, a higher overpotential was required for the OER in the less-basic solution. It is desirable to develop an OER catalyst with lower overpotential losses in less-basic solutions. As shown in Fig. 4a, the required overpotential to achieve a $10 \mathrm{~mA} \mathrm{~cm}^{-2}$ current density was about $0.326 \mathrm{~V}$, which also revealed an advantage for the FeCoNi oxynitride compared with state-of-the-art OER catalysts in a lower-alkalinity electrolyzer (Table $\mathrm{S} 4 \dagger$ ). This finding further demonstrates the superiority of the FeCoNi oxynitride catalysts. The Tafel slope of the FeCoNi oxynitride ( $63.8 \mathrm{mV}$ per decade) was lower than those of $\mathrm{IrO}_{2}$ (87.3 $\mathrm{mV}$ per decade), $\mathrm{RuO}_{2}(136.1 \mathrm{mV}$
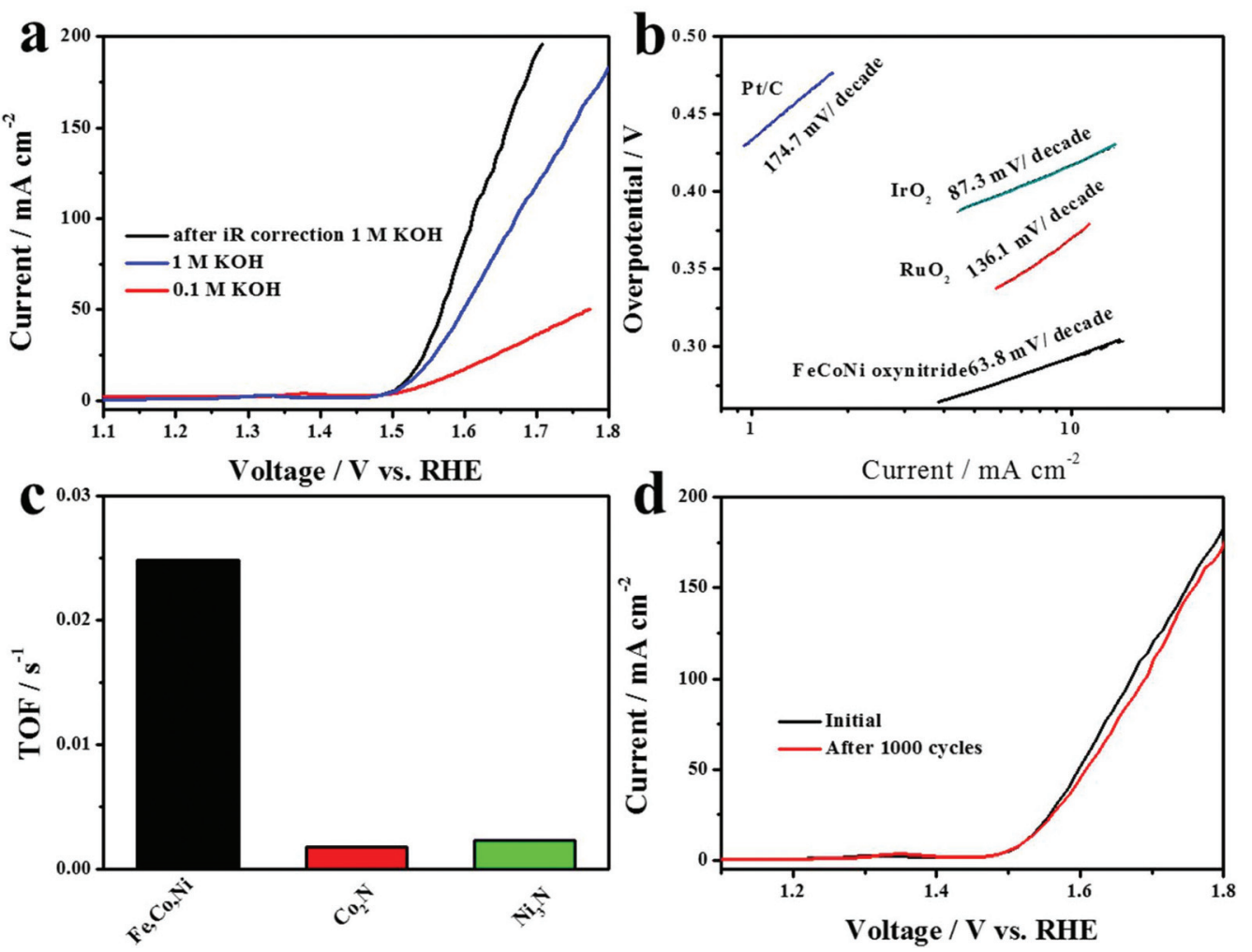

Fig. 4 (a) Comparison of the linear sweep voltammetry (LSV) curves of the FeCoNi oxynitride with or without iR correction and an LSV curve measured in $0.1 \mathrm{M} \mathrm{KOH}$ (without $i R$ correction). (b) Tafel plots of the samples. (c) TOF values calculated from the current at $\eta=0.35 \mathrm{~V}$. (d) Polarization curves after $1000 \mathrm{CV}$ cycles with the FeCoNi oxynitride electrode. 
per decade), and $\mathrm{Pt} / \mathrm{C}$ (174.7 $\mathrm{mV}$ per decade), revealing its superior reaction kinetics (Fig. 4b). To further assess the OER catalytic ability, the turnover frequency (TOF) of the obtained catalysts at an $\eta$ of $0.35 \mathrm{~V}$ is presented here (Fig. 4c). We found that the FeCoNi oxynitride displayed the highest TOF of $\sim 2.49 \times$ $10^{-2} \mathrm{~s}^{-1}$, which was $\sim 13.9$ and $\sim 10.6$ times higher than those of $\mathrm{Co}_{2} \mathrm{~N}$ and $\mathrm{Ni}_{3} \mathrm{~N}$, respectively. The superior OER activity of the FeCoNi oxynitride can be attributed to the synergistic effects of the core-shell structures. The strong electronic interactions provided reliable electronic transmission, which enabled the high electrical conductivity of the FeCoNi oxynitride efficiently (Fig. S12†). Apart from OER activity, durability is another important factor in the appraisal of an advanced catalyst. EELS elemental mapping of the FeCoNi oxynitride after cycling was performed (Fig. S13†). Compared with the initial FeCoNi oxynitride, the core-shell structure was maintained with the homogeneously dispersed nitride as the core and the oxide as the shell, demonstrating the excellent durability of FeCoNi oxynitride materials. After the stability test, the chemical formula of the core-shell structure became $\mathrm{Fe}_{1.31} \mathrm{Co}_{1.82} \mathrm{Ni}_{3.51} \mathrm{~N}_{1.0} \mathrm{O}_{0.0}$ for the core and $\mathrm{Fe}_{0.64} \mathrm{Co}_{0.31} \mathrm{Ni}_{0.38} \mathrm{~N}_{0.0} \mathrm{O}_{1.0}$ for the shell (Fig. S14 $\dagger$ ). After cycling, the valence state of Fe increased in both the core and shell. It is interesting to note that the valence state of Co is higher in the shell than in the core after the reaction. The valence state of Ni remained nearly the same after the reaction (Table S3†). XRD is performed on the used FeCoNi oxynitride sample, as shown in Fig. S15. $\dagger$ The crystal structures of the FeCoNi oxynitride sample do not change greatly after the cycle, which clearly suggests that the FeCoNi oxynitride materials are stable during the OER process. As shown in Fig. 4d, after 1000 cycles, the polarization curve for the FeCoNi oxynitride displayed an onset potential similar to the initial potential, with a slightly positive shift to a higher potential. This is further evidence of the excellent durability of the FeCoNi oxynitride electrocatalyst with a core-shell structure. High-temperature hydrogenation was performed to treat the FeCoNi oxynitride, and the oxide shell was destroyed (Fig. S16†). Significantly deteriorated OER behavior was observed after 30 cycles (Fig. S17 $\dagger$ ), which is further evidence of the significance of the oxide shells.

Density functional theory simulations were carried out to gain a deeper understanding of the structural effect on the OER. We compared four different surface structures, including an $\mathrm{Ni}_{3} \mathrm{~N}$ surface, an $\mathrm{Ni}_{3} \mathrm{~N}$ surface doped with $\mathrm{Fe}$ and $\mathrm{Co}$, an $\mathrm{Fe}_{3} \mathrm{O}_{4}$ surface, and an $\mathrm{Fe}_{3} \mathrm{O}_{4}$ surface doped with $\mathrm{Ni}$ and Co. The free energy diagram of the OER with four electrons, shown in Fig. 5a, was constructed as described in the ESI. $\dagger$ It was found that metallic $\mathrm{Ni}_{3} \mathrm{~N}$ and $\mathrm{Ni}_{3} \mathrm{~N}$ alloy surfaces generally had very large energy barriers for the $\mathrm{OOH}^{*}$ formation step. The alloy effect was very small in the $\mathrm{Ni}_{3} \mathrm{~N}$ structure. In the oxide structure, doping with $\mathrm{Ni}$ and Co improved the reaction energetics. With the formation of the nitride/oxide core-shell structure, the reaction energetics might be further tuned to the inbetween regions toward optimal energies. The binding energies of different intermediate species are shown in Fig. 5b. Generally, metallic nitride structures bind the intermediate species stronger than oxides do, and the binding energies vary with doping. These results indicate that the nitride-core, oxideshell structure would provide favorable energetic pathways for the OER, which explains the excellent performance in experiments.

The superior catalytic performance of the core-shell structured FeCoNi oxynitride in the OER can be attributed to the synergistic effects of the homogeneously dispersed multivariant components and the unique core-shell structure. First, the metallic-phase nitride core ensures the excellent electrical conductivity of the FeCoNi oxynitride electrocatalyst. Second, according to previous reports, the adsorption energy of $\mathrm{OH}$ is too strong on an Fe-based material surface and too weak on Co-based and Ni-based material surfaces. ${ }^{10,23}$ The synergistic interplay among $\mathrm{Fe}$, $\mathrm{Co}$, and $\mathrm{Ni}$ produced a favorable local coordination environment and an electronic structure that
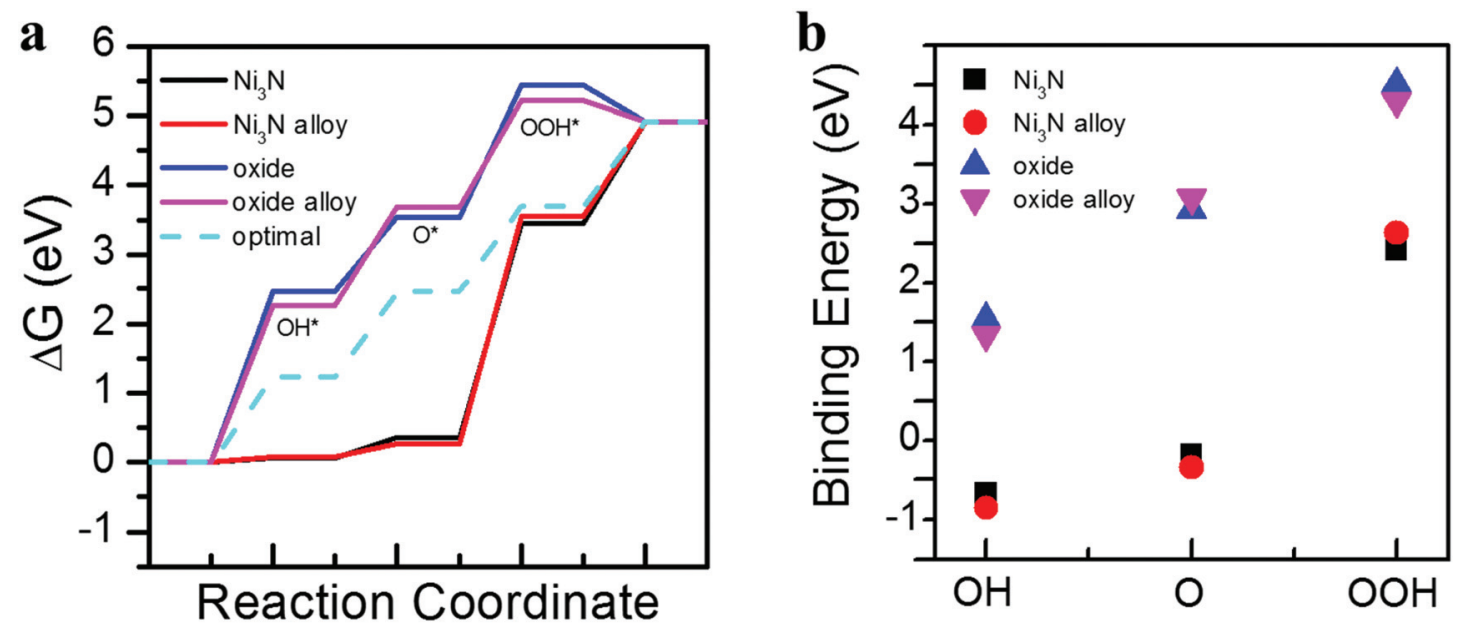

Fig. 5 (a) Free energy diagram of different intermediate species on different surfaces; (b) binding energies of intermediate species on different surfaces. 
optimized the adsorption energy and improved the OER behavior. Third, the oxide shell effectively prevented electrode corrosion and enabled the high OER stability. These unique advantages significantly promoted the reaction kinetics and enhanced the stability of this Earth-abundant FeCoNi oxynitride catalyst for the OER.

\section{Conclusions}

In summary, we successfully developed a novel core-shell structure FeCoNi oxynitride, with nitride $\mathrm{Fe}_{0.70} \mathrm{Co}_{0.56} \mathrm{Ni}_{0.92} \mathrm{~N}_{1.0} \mathrm{O}_{0.06}$ as the core and oxide $\mathrm{Fe}_{0.48} \mathrm{Co}_{0.1} \mathrm{Ni}_{0.21} \mathrm{~N}_{0.05} \mathrm{O}_{1.0}$ as the shell, as an extraordinary OER catalyst in alkaline media. FeCoNi oxynitride catalysts displayed a greatly reduced onset potential and higher current density than their single- or dual-component counterparts. The unique core-shell architectures with Fe, Co, or Ni ternary metal components homogeneously dispersed in the nitride core enabled a synergistic effect for the OER process, and the oxide shell endowed the FeCoNi oxynitride with high stability. The strategy of employing a multimetallic component to improve the catalytic activity and a protective shell to enhance catalytic stability should be broadly applicable to a range of important reactions involved in next-generation energy conversion and storage schemes. The novel material also displayed performance comparable to or superior to that of a state-ofthe-art catalyst.

\section{Conflicts of interest}

The authors declare no competing financial interest.

\section{Acknowledgements}

This work was financially supported by the National Natural Science Foundation of China (No. 21676128, 21576123, 21476098 and 21471069). S. D. and H. Z. were sponsored by the Division of Chemical Sciences, Geosciences, and Biosciences, Office of Basic Energy Sciences, US Department of Energy. Electron microscopy at Oak Ridge National Laboratory (S. Z. Y.) was supported by the US Department of Energy, Office of Science, Basic Energy Sciences, Materials Sciences and Engineering Division, and was performed in part as a user proposal at the Oak Ridge National Laboratory Center for Nanophase Materials Sciences, which is a DOE Office of Science User Facility.

\section{References}

1 C. Niether, S. Faure, A. Bordet, J. Deseure, M. Chatenet, J. Carrey, B. Chaudret and A. Rouet, Nat. Energy, 2018, 3, 476-483.
2 M. Sun, H. J. Liu, Y. Liu, J. H. Qu and J. H. Li, Nanoscale, 2015, 7, 1250-1269.

3 M. Sun, D. Davenport, H. J. Liu, J. H. Qu, M. Elimelech and J. H. Li, J. Mater. Chem. A, 2018, 6, 2527-2539.

4 M. Sun, G. Zhang, H. J. Liu, Y. Liu and J. H. Li, Sci. China Mater., 2015, 58, 683-692.

5 J. S. Luo, J. H. Im, M. T. Mayer, M. Schreier, M. K. Nazeeruddin, N. G. Park, S. D. Tilley, H. J. Fan and M. Grätzel, Science, 2014, 345, 1593-1596.

6 X. J. Zhao, P. Pachfule, S. Li, J. R. J. Simke, J. Schmidt and A. Thomas, Angew. Chem., Int. Ed., 2018, 57, 8921-8926.

7 M. Sun, H. J. Liu, J. H. Qu and J. H. Li, Adv. Energy Mater., 2016, 6, 1600087.

8 G. Zhang, G. C. Wang, Y. Liu, H. J. Liu, J. H. Qu and J. H. Li, J. Am. Chem. Soc., 2016, 138, 14686-14693.

9 M. R. Gao, W. C. Sheng, Z. B. Zhuang, Q. R. Fang, S. Gu, J. Jiang and Y. S. Yan, J. Am. Chem. Soc., 2014, 136, 70777084 .

10 B. Zhang, X. L. Zheng, O. Voznyy, R. Comin, M. Bajdich, M. García-Melchor, L. L. Han, J. X. Xu, M. Liu, L. R. Zheng, F. P. G. de Arquer, C. T. Dinh, F. J. Fan, M. J. Yuan, E. Yassitepe, N. Chen, T. Regier, P. F. Liu, Y. H. Li, P. De Luna, A. Janmohamed, H. L. L. Xin, H. G. Yang, A. Vojvodic and E. H. Sargent, Science, 2016, 352, 333-337.

11 R. D. L. Smith, M. S. Prévot, R. D. Fagan, Z. P. Zhang, P. A. Sedach, M. K. J. Siu, S. Trudel and C. P. Berlinguette, Science, 2013, 340, 60-63.

12 M. Gong, Y. G. Li, H. L. Wang, Y. Y. Liang, J. Z. Wu, J. G. Zhou, J. Wang, T. Regier, F. Wei and H. J. Dai, J. Am. Chem. Soc., 2013, 135, 8452-8455.

13 Y. Yang, H. L. Fei, G. D. Ruan and J. M. Tour, Adv. Mater., 2015, 27, 3175-3180.

14 S. Dou, L. Tao, J. Huo, S. Y. Wang and L. M. Dai, Energy Environ. Sci., 2016, 9, 1320-1326.

15 J. Suntivich, K. J. May, H. A. Gasteiger, J. B. Goodenough and Y. Shao-Horn, Science, 2011, 334, 1383-1385.

16 K. Xu, P. Z. Chen, X. L. Li, Y. Tong, H. Ding, X. J. Wu, W. S. Chu, Z. M. Peng, C. Z. Wu and Y. Xie, J. Am. Chem. Soc., 2015, 137, 4119-4125.

17 P. Z. Chen, K. Xu, Z. W. Fang, Y. Tong, J. C. Wu, X. L. Lu, X. Peng, H. Ding, C. Z. Wu and Y. Xie, Angew. Chem., Int. Ed., 2015, 54, 14710-14714.

18 S. Jing, ACS Energy Lett., 2017, 2, 1937-1938.

19 F. Song and X. L. Hu, Nat. Commun., 2014, 5, 4477.

20 X. H. Gao, H. X. Zhang, Q. G. Li, X. G. Yu, Z. L. Hong, X. W. Zhang, C. D. Liang and Z. Lin, Angew. Chem., Int. Ed., 2016, 55, 6290-6294.

21 L. Trotochaud, S. L. Young, J. K. Ranney and S. W. Boettcher, J. Am. Chem. Soc., 2014, 136, 6744-6753.

22 M. S. Burke, M. G. Kast, L. Trotochaud, A. M. Smith and S. W. Boettcher, J. Am. Chem. Soc., 2015, 137, 3638-3648.

23 J. Zhang, T. Wang, D. Pohl, B. Rellinghaus, R. H. Dong, S. H. Liu, X. D. Zhuang and X. L. Feng, Angew. Chem., Int. Ed., 2016, 55, 6702-6707.

24 J. X. Feng, H. Xu, Y. T. Dong, S. H. Ye, Y. X. Tong and G. R. Li, Angew. Chem., Int. Ed., 2016, 55, 3694-3698. 
25 Z. B. Zhuang, W. C. Sheng and Y. S. Yan, Adv. Mater., 2014, 26, 3950-3955.

26 C. C. L. McCrory, S. Jung, I. M. Ferrer, S. M. Chatman, J. C. Peters and T. F. Jaramillo, J. Am. Chem. Soc., 2015, 137, 4347-4357.

27 K. Fan, H. Chen, Y. F. Ji, H. Huang, P. M. Claesson, Q. Daniel, B. Philippe, H. K. Rensmo, F. S. Li, Y. Luo and L. C. Sun, Nat. Commun., 2016, 7, 11981.

28 J. Bao, X. D. Zhang, B. Fan, J. J. Zhang, M. Zhou, W. L. Yang, X. Hu, H. Wang, B. C. Pan and Y. Xie, Angew. Chem., Int. Ed., 2015, 54, 73997404.
29 D. Li, H. Baydoun, C. N. Verani and S. L. Brock, J. Am. Chem. Soc., 2016, 138, 4006-4009.

$30 \mathrm{H}$. Hu, B. Y. Guan, B. Y. Xia and X. W. Lou, J. Am. Chem. Soc., 2015, 137, 5590-5595.

31 L. Han, X. Y. Yu and X. W. Lou, Adv. Mater., 2016, 28, 46014605.

32 L. Qian, Z. Y. Lu, T. H. Xu, X. C. Wu, Y. Tian, Y. P. Li, Z. Y. Huo, X. M. Sun and X. Duan, Adv. Energy Mater., 2015, 5, 1500245.

33 C. W. Tung, Y. Y. Hsu, Y. P. Shen, Y. X. Zheng, T. S. Chan, H. S. Sheu, Y. C. Cheng and H. M. Chen, Nat. Commun., 2015, 6, 8106. 